\title{
Quantitative Proteomics Analysis of Natural Lignocelluloses Degraded by Aspergillus fumigatus G-13 Based on iTRAQ
}

\author{
Jinda Li ${ }^{1,2}$, Qian Feng ${ }^{1,2}$, Xia Du ${ }^{1,2}$, Hong Yan ${ }^{1,2 *}$ \\ ${ }^{1}$ College of Chemical and Environmental Engineering, Harbin University of Science and Technology, \\ Harbin 150040, China \\ ${ }^{2}$ Key Laboratory of Green Chemical Technology of College of Heilongjiang Province, Harbin 150040, China
}

Received: 22 December 2019

Accepted: 26 February 2020

\begin{abstract}
Aspergillus fumigatus G-13 has a strong potential to degrade lignocellulose. The study identified the secreted proteins of natural lignocellulosic substrates fermented by Aspergillus fumigatus G-13 by iTRAQ, and performed bioinformatics analysis on the differential proteins obtained. The effects of pretreatment on the production of ligninase and the degradation of natural lignocellulose by strains were studied. The results showed that with Robinia as fermentation substrate, 897 differential proteins were found before and after pretreatment, and the expression was up-regulated by 432 and the expression was down-regulated by 465 . Using walnut shell as fermentation substrate, there were 1122 differential proteins, with 802 expressions up-regulated and 20 expressions down-regulated. The Gene Ontology (GO) suggested that these differential proteins were mainly involved in transport activity, catalytic activity and enzyme regulation activity. The pretreated natural lignocellulosic substrate was fermented by Aspergillus fumigatus G-13, exhibited high lignin-degrading enzyme activity and high protein expression. It is shown that pretreatment affects the metabolic pathways of the fungi cells, increases the production of key enzymes, such as NADH-ubiquinone oxidoreductase, hyphae catalase CAT1, flavin-binding monooxygenase, urinary acid-1,2-dioxygenase, catechol dioxygenase, glyoxalase, FDA monooxygenase, fatty acid oxygenase, etc. Simultaneous pretreatment increases the methyl metabolism capacity of the strain and stimulates the growth of the mycelium cells.
\end{abstract}

Keywords: Aspergillus fumigatus, pretreatment, iTRAQ, ligninase activity, natural lignocellulose

\section{Introduction}

Lignin is the second abundant organic polymer on the earth. It is a heterogeneous alkyl-aromatic biopolymer,

*e-mail: yanhong204821@aliyun.com which is produced in pulp and paper industry and its natural source is plant cell wall [1]. However, due to the irregular matrix structure of lignin and the lack of standard, repetitive covalent products, it is very difficult to biodegrade [2]. In recent years, due to the outstanding performance of Aspergillus in degradation of lignin in paper-making wastewater and agricultural 
wastes, much attention has been paid to it. Aspergillus niger, Aspergillus flavus and Aspergillus fumigatus are widely used in the biodegradation of agricultural wastes such as rice straw, corn straw and cotton straw, and in the biological treatment of printing and dyeing wastewater from papermaking, aiming at reducing environmental pollution and producing biomass fuels [3-7]. However, in order to achieve an acceptable rate of enzymatic hydrolysis, the natural lignocellulose must first be pretreated to reduce the substrate's intractability. Pretreatment completed various changes to biomass, typically including the hydrolysis of hemicellulose to varying degrees, solubilization of lignin and carbohydrate oligomers, and increased the accessibility of ligninase to lignin [8]. According to Chen et al., when straw was treated with a weak base, the removal rates of hemicellulose and lignin were $91.8 \%$ and $97.4 \%$, respectively, and the biodegradation efficiency of lignin was also significantly improved [9]. Ligninase such as manganese peroxidase, lignin peroxide and laccase can effectively depolymerize, degrade and activate the lignin component of plant cell walls. Therefore, a highly sensitive proteomics technique can be used to explore its secretion mechanism, which helps to discover new lignocellulolytic hydrolase and reveal its hydrolysis mechanism. Although gene expression, such as transcriptome analysis, has been widely used in such analysis, it has limitations such as RNA stabilization, primer selection, a large number of false positives, and false negative results, while proteomics technology is very advanced and sensitive, suitable for identifying a variety of proteins from complex biological samples. In recent years, the rapid development of high-sensitivity quantitative proteomics technology has made it possible to comprehensively analyze protein expression, discover new enzymes and quantitative expression them, thereby highlighting the underlying molecular mechanisms [10]. Sunil et al. used quantitative iTRAQ technology to analyze the secreted proteome of Thermobifida fusca using cellulose as a substrate, and found that peroxidase, catalase, cytochrome $\mathrm{C}$ oxidase and superoxide dismutase are involved in the degradation of plant cell walls [11]. In the same year, Liang et al. analyzed the secreted proteome of Aspergillus niger and revealed various hydrolases [12]. Deangeli et al. analyzed in detail the new pathway mechanism of bacterial degradation of 4-hydroxyphenylacetate of lignin from the perspective of proteomics. In addition, some researchers have used proteomics techniques to identify related enzyme components and metabolic pathways that play a role in lignin degradation, such as the discovery of transglucosylase, callose $\beta-1,3$-exonuclease and some special oxidases [13-15].

Although quantitative secretory proteomics studies of lignin degradation have attracted attention for many years, there has been no report on traditional material degradation proteomics of iTRAQ-based Aspergillus. Usually, the conversion of lignin biomass to soluble sugars is also a major difficulty in current research [16]. Ligninase is a series of enzymes involved in the degradation of lignin, such as laccase (Lac), manganese peroxidase $(\mathrm{MnP})$ and lignin peroxidase (LiP). Effective hydrolysis of lignin biomass involves the release and decomposition of long-chain polysaccharides, which requires the relaying action of these enzymes [17]. The study used a strain of Aspergillus fumigatus G-13 with lignin degradation ability preserved in the laboratory for lignin degradation enzyme activity determination. The proteomics analysis of the sample was carried out by using iTRAQ technology, and the enzymatic composition and classification of this strain involved in the degradation of natural lignocellulose were obtained. Significantly different proteins screened for quantitative results were subjected to GO, pathway, COG functional annotation and GO and pathway enrichment analysis of differential proteins. In this way, we investigated the high secretory expression and mechanism of the exogenous protein of the strain acting on natural lignocellulose.

\section{Materials and Methods}

\section{Strains and Natural Lignin Samples}

The laboratory isolated the Aspergillus fumigatus G-13 strain from the soil near the sewage discharge port of a paper mill in Harbin and identified it.

The natural lignin samples involved in the experiment were Robinia and walnut shells, all purchased from Songshan Forest Farm, Gongyi City, Henan Province, China.

\section{Preparation of the Medium}

PDA medium: $200 \mathrm{~g}$ of potato peeled and diced, placed in a beaker and added with water $1 \mathrm{~L}$, boiled for $30 \mathrm{~min}$, filtered through gauze, and the filtrate was retained. $20 \mathrm{~g}$ of glucose, $20 \mathrm{~g}$ of agar powder, and an appropriate amount of distilled water were added to the filtrate to constant volume of $1 \mathrm{~L}$. After sub-packaging, autoclave at $120^{\circ} \mathrm{C}$ for $30 \mathrm{~min}$.

Preparation of a large amount of elemental nutrient salt (solution 1): $0.2150 \mathrm{~g} \mathrm{KH}_{2} \mathrm{PO}_{4}, 0.2160 \mathrm{~g}\left(\mathrm{NH}_{4}\right)_{2} \mathrm{SO}_{4}$, $0.0073 \mathrm{~g} \mathrm{MgSO}_{4}$, and $0.0150 \mathrm{~g} \mathrm{CaCl}_{2}$ per $100 \mathrm{~mL}$ of nutrient salt.

Preparation of trace element nutrient salt (solution 2): $\mathrm{CoCl}_{2} \cdot 6 \mathrm{H}_{2} \mathrm{O} 3.9 \mathrm{~g} / \mathrm{L}, \mathrm{ZnSO}_{4} \cdot 7 \mathrm{H}_{2} \mathrm{O} 1.4 \mathrm{~g} / \mathrm{L}, \mathrm{MnSO}_{4} \cdot \mathrm{H}_{2} \mathrm{O}$ $1.6 \mathrm{~g} / \mathrm{L}, \mathrm{FeSO}_{4} \cdot 7 \mathrm{H}_{2} \mathrm{O} 5 \mathrm{~g} / \mathrm{L}$, dissolved and constant volume to $1 \mathrm{~L}$.

\section{Preparation of Bacterial Suspension}

The preserved A. fumigatus PDA slant medium was taken out, and the fungal spores were washed with sterile water to prepare a spore suspension of $10^{6}$ cells $/ \mathrm{mL}$ (measured by blood cell counting), which 
was store in a refrigerator at $4^{\circ} \mathrm{C}$ for reserve, and the sample inoculation amount is $3.5 \mathrm{~mL} /$ bottle.

\section{Sample Pretreatment}

Experimental group: physical grinding to a particle size of 60-80 mesh, alkali pretreatment was $8 \%$ $\mathrm{Ca}(\mathrm{OH})_{2}$ solution at $60^{\circ} \mathrm{C}$ for $48 \mathrm{~h}$. The pretreated sample is washed with distilled water until the $\mathrm{pH}$ value does not change and is dried to constant weight at $60^{\circ} \mathrm{C}$.

Control group: Physically ground to a particle size of 60-80 mesh, the sample was washed with distilled water until the $\mathrm{pH}$ was no longer changed, and dried to constant weight at $60^{\circ} \mathrm{C}$.

\section{Fermentation Culture and Protein Extraction}

Add $5 \mathrm{~g}$ of natural lignocellulose sample to the medium, and add solution 1 and $0.1 \%$ solution 2 according to the system solid-liquid ratio 2:3. After autoclaving at $120^{\circ} \mathrm{C}$ for $20 \mathrm{~min}, 3.5 \mathrm{~mL}$ of spore suspension was added. The total protein was centrifuged at $10,000 \times \mathrm{g}$, centrifuged at $4^{\circ} \mathrm{C}$ for $15 \mathrm{~min}$, and clarified by filtration through a $0.25 \mu \mathrm{m}$ filter. The filtrate was concentrated by lyophilization and redissolved in $0.1 \mathrm{M}$ triethylammonium bicarbonate buffer (TEAB) and desalted using a 5-kDa cut-off spin filter. Fig. 1 shows the strain culture process, the enzyme activity assay process, and iTRAQ sample delivery.

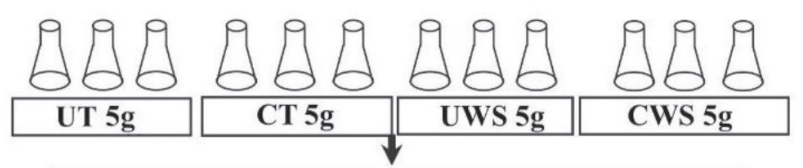

Crude enzyme $3.5 \mathrm{~mL}$, Solution 1 (equal to sample volution), Solution 2 ( $1 \%$ of solution 1 volume)

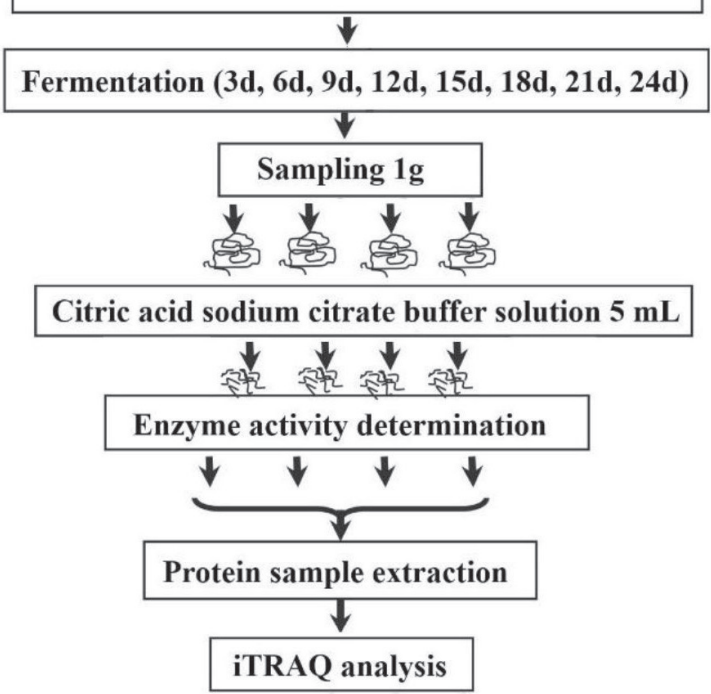

Fig. 1. Strain culture, enzyme activity determination and iTRAQ sample preparation process.

\section{Enzyme Activity Assay}

Manganese peroxidase (Mnp) activity assay: Add $3.4 \mathrm{~mL}$ of acetic acid-sodium acetate buffer solution (concentration: $200 \mathrm{mmol} / \mathrm{L}, \mathrm{pH} 4.5$ ) to the reaction system, and add $0.1 \mathrm{~mL}$ of $1.6 \mathrm{mmol} / \mathrm{L} \mathrm{MnSO}_{4}$ solution and $0.4 \mathrm{~mL}$ of crude enzyme solution. Finally, $0.1 \mathrm{ml}$ of $1.6 \mathrm{mmol} / \mathrm{L} \mathrm{H}_{2} \mathrm{O}_{2}$ solution was added to start the reaction, and the reaction was carried out at $37^{\circ} \mathrm{C}$ for $3 \mathrm{~min}$, and the absorbance at $240 \mathrm{~nm}$ was measured. One enzyme unit (U) is defined as the amount of enzyme required to oxidize $1 \mu \mathrm{mol} \mathrm{Mn}^{2+}$ per minute to $\mathrm{Mn}^{3+}$. Each sample parallel operation three times and then averaged [18].

Lignin peroxidase (Lip) activity assay: The reaction solution contained $1 \mathrm{~mL}$ of $15 \mathrm{mmol} / \mathrm{L}$ resveratrol solution, $1.5 \mathrm{~mL}$ of sodium tartrate buffer (concentration of $250 \mathrm{mmol} / \mathrm{L}, \mathrm{pH}$ of 3 ) and $0.4 \mathrm{~mL}$ of crude enzyme solution. Finally, $0.1 \mathrm{~mL}$ of $20 \mathrm{mmol} / \mathrm{L} \mathrm{H}_{2} \mathrm{O}_{2}$ solution was added to initiate the reaction, and the absorbance at $0,1,2$ and 3 min was measured at $310 \mathrm{~nm}$ ultraviolet light. One enzyme unit (U) is defined as the amount of enzyme required to oxidize $1 \mu \mathrm{mol}$ of resveratrol per minute to become veratraldehyde within $3 \mathrm{~min}$ before the reaction. Each sample was run in parallel three times and then averaged [19].

Laccase activity (Lac) assay: The reaction solution contained $0.5 \mathrm{~mL} 0.5 \mathrm{mmol} / \mathrm{L}$ ABTS solution, $2 \mathrm{~mL}$ of acetic acid-sodium acetate buffer solution (concentration of $200 \mathrm{mmol} / \mathrm{L}, \mathrm{pH}$ of 5) and $0.5 \mathrm{~mL}$ of crude enzyme solution. The change in absorbance was measured at $420 \mathrm{~nm}$ after reaction for $3 \mathrm{~min}$ at $28^{\circ} \mathrm{C}$. One enzyme unit (U) is defined as the amount of enzyme required to oxidize $1 \mu \mathrm{mol}$ ABTS per minute to ABTS free radical within $3 \mathrm{~min}$ before the reaction. Each sample parallel operation three times and then averaged [20].

\section{iTRAQ Analysis of Protein Samples \\ Proteolysis and iTRAQ Llabeling}

Proteolysis: $100 \mu \mathrm{g}$ of protein was accurately taken from each sample. Trypsin was added in a ratio of protein : enzyme $=20: 1$, and enzymolysised at $37^{\circ} \mathrm{C}$ for $4 \mathrm{~h}$. Trypsin was added once more in the above proportion, and enzymatic hydrolysis was continued for $8 \mathrm{~h}$ at $37^{\circ} \mathrm{C}$.

iTRAQ labeling: After trypsin digestion, the peptide segments were dried using a vacuum centrifuge pump. The peptide segments were redissolved with 0.5 M TEAB and the iTRAQ labeling was performed according to the manual. Each set of peptides was labeled with a different iTRAQ tag and placed at room temperature for $2 \mathrm{~h}$. The labeled peptide groups of each group were mixed and subjected to liquid phase separation using an SCX column. 


\section{SCX Separation}

The sample was subjected to liquid phase separation using a Shimadzu LC-20AB liquid phase system with a separation column of $4.6 \times 250 \mathrm{~mm}$ type Ulremexx SCX column. The labeled dried peptides were redissolved with $4 \mathrm{~mL}$ buffer $\mathrm{A}\left(25 \mathrm{mM} \mathrm{NaH} \mathrm{PO}_{4}\right.$ in $25 \% \mathrm{ACN}$, $\mathrm{pH}$ 2.7). Gradient elution was carried out at a rate of $1 \mathrm{~mL} / \mathrm{min}$ after column entry. First eluted in 5\% buffer $\mathrm{B}\left(25 \mathrm{mM} \mathrm{NaH} \mathrm{PO}_{4}, 1 \mathrm{M} \mathrm{KCl}\right.$ in $\left.25 \% \mathrm{ACN}, \mathrm{pH} 2.7\right)$ for $7 \mathrm{~min}$, followed by a linear gradient of $20 \mathrm{~min}$ to increase buffer B from $5 \%$ to $60 \%$. Finally, the ratio of buffer B was increased to $100 \%$ within 2 minutes and kept for 1 minute, then returned to $5 \%$ for $10 \mathrm{~min}$. The whole elution process was monitored at $214 \mathrm{~nm}$ absorbance, and 20 components were screened out. Each component was desalted by StrataX desalting column and then Frozen drained.

\section{LC-ESI-MS/MS Analysis Based on Triple TOF 5600}

The dried components were redissolved with buffer A $(5 \%$ ACN, $0.1 \%$ FA) to a concentration of about $0.5 \mu \mathrm{g} / \mu \mathrm{l}$, and centrifuged at $20000 \mathrm{~g}$ for $10 \mathrm{~min}$ to remove insoluble materials. Each component was loaded with $5 \mu \mathrm{l}$ (about $2.5 \mu \mathrm{g}$ of protein) and separated by a Shimadzu LC-20AD model nanoliter liquid chromatograph. The column used consisted of a Trap column and an analytical column. The separation procedure is as follows: first load the sample onto the Trap column within $4 \mathrm{~min}$ at a flow rate of 8 $\mu \mathrm{L} / \mathrm{min}$. The sample is then taken to the analytical column, separated by an analytical gradient with a total flow rate of $300 \mu \mathrm{L} / \mathrm{min}$, and transported to the mass spectrometry system. Firstly, the buffer B was eluted at $5 \%$ buffer B $(95 \% \mathrm{ACN}, 0.1 \% \mathrm{FA})$ for $5 \mathrm{~min}$, followed by a 35-minute linear gradient to increase the proportion of buffer B from $5 \%$ to $35 \%$, and then increased to $60 \%$ in the next $5 \mathrm{~min}$. Then buffer B was increased to $80 \%$ in 2 minutes and kept for 2 minutes. Finally, restored to $5 \%$ in $1 \mathrm{~min}$ and balanced for $10 \mathrm{~min}$ under this condition. The machine used was Triple TOF 5600 (AB SCIEX, Concord, ON), the ion source was Nanospray III source (AB SCIEX, Concord, ON), and the emitter was a quartz material drawn needle (New Objectives, Woburn, MA). During data acquisition, the parameters of the machine are set as follows: the ion source spray voltage is $2.5 \mathrm{kV}$, the nitrogen pressure is 30 psi (14.5psi 1 lbar), the spray pressure is $15 \mathrm{psi}$, and the spray interface temperature is $150^{\circ} \mathrm{C}$; The scan mode is reflection mode with a resolution of $\geq 30,000$; It accumulates $250 \mathrm{~ms}$ in the first-order mass spectrum and scans only ions with a charge of $2+5+$; The first 30 samples with strength over 120 CPS were scanned, and $3.3 \mathrm{~s}$ was a cycle; The transmission window of the second quadrupole (Q2) is set to $100 \%$ efficiency at $100 \mathrm{Da}$; The frequency of the pulsed radio frequency is $11 \mathrm{kHz}$; the detection frequency of the detector is
$40 \mathrm{GHz}$; Each scanned particle signal is recorded four times in four channels and then combined into data; For iTRAQ-like projects, the energy of ion fragmentation is set to $35 \pm 5 \mathrm{eV}$; The dynamic elimination of the parent ion is set to be half of the peak time (about $15 \mathrm{~s}$ ), and the fragmentation of the same parent ion is not more than 2 times.

\section{Data Analysis}

Convert the raw data files obtained by Orbitrap to MGF files and search for MGF files using Proteome Discoverer 1.2 (PD 1.2, Thermo) [5600 msconverter]. Using the search engine to select the decoy checkbox, the decoy database is automatically searched on Mascot, and a random sequence of the database was generated in the checkbox, the original spectrum and the real database were tested. To reduce the probability of pseudo-polypeptide recognition, a polypeptide that recognizes a significance score in the $99 \%$ confidence interval will be calculated. Protein identification involves at least one unique peptide. For protein quantification, a protein is required to contain at least two unique peptides. Based on the median ratio, the quantitative protein ratio was weighted and normalized. $\mathrm{P}$ value $<0.05$ and $\mathrm{F}>1.2$ were used as significant differences.

Functional annotation of proteins for non-redundant protein databases (NR; NCBI) using the Blast2GO program. The KEGG database and the KOG database were used to classify and group these identified proteins. Gene Ontology (GO) is the international standardization of gene function classification systems. It provides a set of dynamic update control vocabulary to describe the genes and gene product properties in an organism. GO has three ontology that describe molecular function, cellular composition, and biological processes. KOG is a database of homologous classification of proteins. Every protein in KOG should be from the same ancestral protein. KEGG PATHWAY is a set of manually drawn pathway maps that represent our knowledge of molecular interactions and reaction networks. The numerator is represented as a node, and the biological relationship between the two nodes is represented as an edge (line) [21, 22].

\section{Results Analysis}

\section{Analysis of Ligninase Activity Produced by A. fumigatus G-13 Fermented Natural Lignocellulose}

Fig. 2 is the change curve of enzyme activity with time of $A$. fumigatus G-13 fermented natural lignocellulose. In the figure, UT represents a sample of Robinia that has not been chemically pretreated, and CT represents a sample of Robinia that has been chemically pretreated. UWS represents a walnut shell sample that 

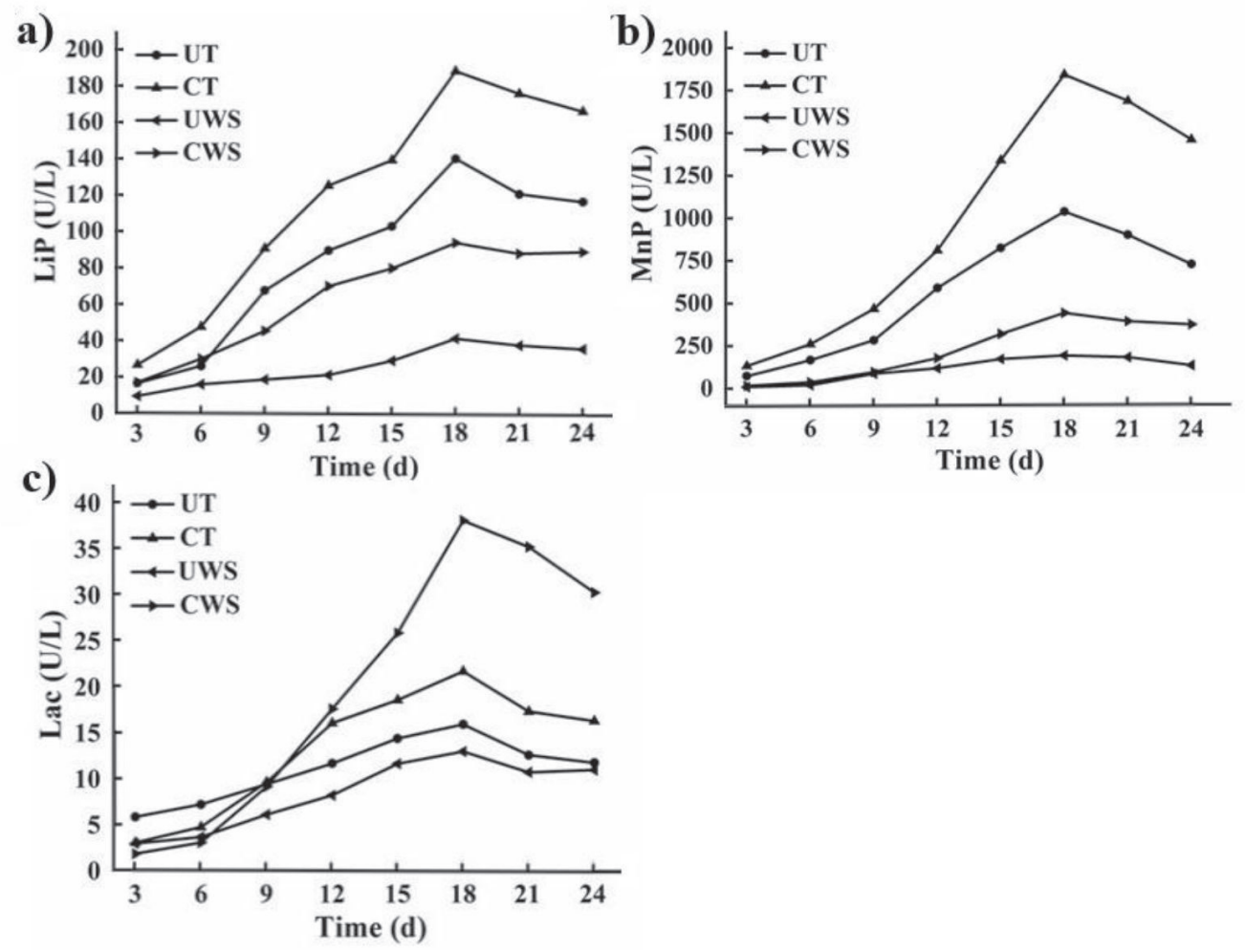

Fig. 2. The changes in enzyme activity of A. fumigatus G-13 fermented Robinia and walnut shell substrates. a) Lignin peroxidase, b) Laccase, c) Manganese peroxidase.

has not been chemically pretreated, and CWS represents a walnut shell sample that has been chemically pretreated. The analysis shows that the lignin-degrading enzyme activity gradually increases to the highest value over time throughout the culture, and then decreases slightly and remains unchanged. The enzyme activity reached a maximum at 15-18 days of culture. It can be seen from this that the lignin degrading enzyme activity of natural lignocellulose substrates treated by chemical pretreatment is significantly increased. By observing the biomass growth of different substrates fermented by $A$. fumigatus $\mathrm{G}-13$, it was found that compared with the unpretreated samples, the pretreated samples by bacterial fermentation were significantly biomass growth. This result is consistent with the enzyme activity assay.

\section{Protein SDS-PAGE Results}

The extracted bacterial protein samples under different substrate conditions were subjected to SDSPAGE electrophoresis. The gel electrophoresis pattern is shown in Fig. 3. Among them, strips 1 and 2 represent sample UT, strips 3 and 4 represent sample CT, strips 5 and 6 represent UWS, and strips 7 and 8 represent sample CWS. The gel electrophoresis showed that the 8 samples had clear bands and no miscellaneous bands. There is also no protein degradation, banding repeatability are qualified.

\section{Mass Spectrometric Identification of Protein Samples}

\section{Differential Protein Point Analysis}

The results of the analysis of the overall protein data are shown in Fig. 4 and Fig. 5. Fig. 4 shows the molecular weight distribution of the protein. The extracellular secretory proteins of A. fumigatus G-13 fermentation medium with different substrates were identified by LC-MS/MS. A total of 3463 proteins were identified by searching the database (NCBInr). As can be seen from the figure below, most proteins are $30-70 \mathrm{kDa}$, and more than $21 \%$ of proteins with molecular weights greater than $100 \mathrm{kDa}$ have been

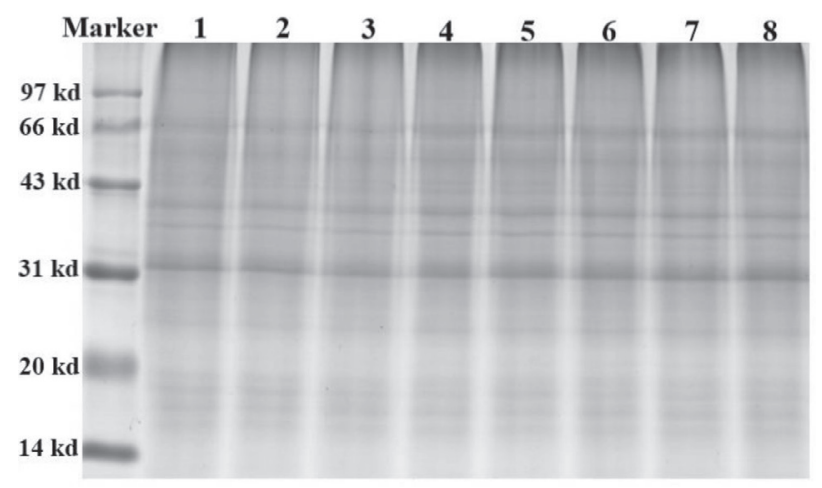

Fig. 3. Detection results of SDS-PAGE. 


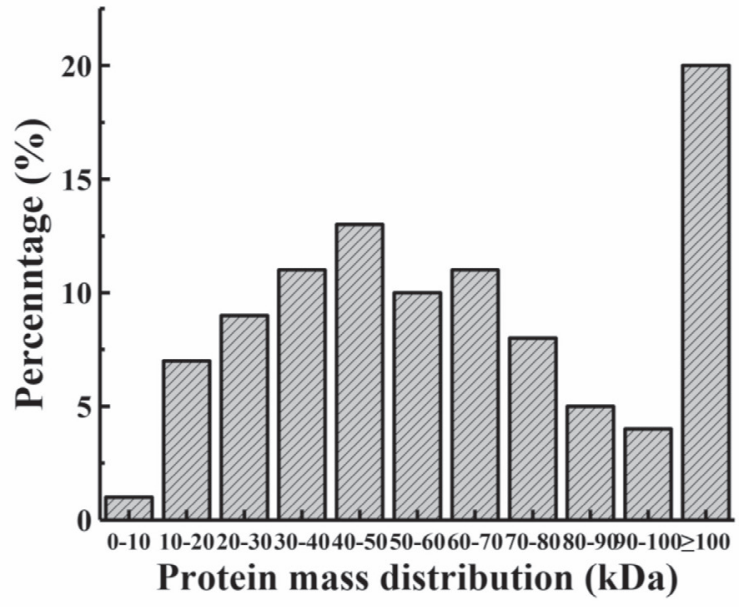

Fig. 4. Protein molecular weight distribution map.

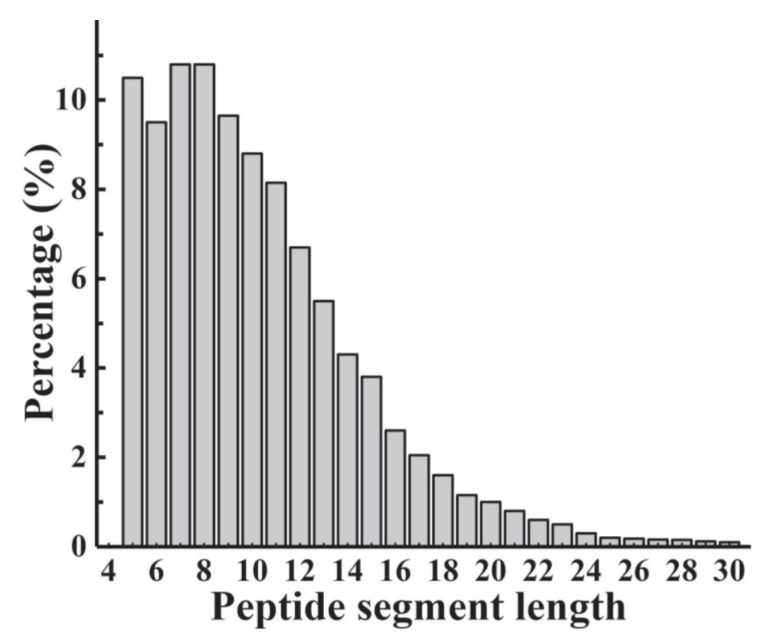

Fig. 5. Peptide length distribution map.

identified. In addition, 11-20 kDa and 71-80 kDa each accounted for about $7 \%$, and the protein with a mass of $0-10 \mathrm{kDa}$ accounted for only about $1 \%$. Fig. 5 is a diagram showing the distribution of peptide segment lengths. The number of amino acids contained in the peptide segment is mainly 5-20.

\section{Analysis of Differential Protein Spots within Group}

The quantitative process of ITRAQ is realized by software IQuant. UT vs CT, UWS vs CWS, UT vs UWS, CT vs CWS are set to compare groups. Significantly different proteins from a single experiment were screened using Fold change $>1.2$ and $\mathrm{Q}$-value $<0.05$. For repeated experimental data, the final differential proteins were screened under two conditions: Fold change $>1.2$ (average of the ratio of all comparison groups) and $\mathrm{P}$-value $<0.05$ (T-test of all comparison groups). Fig. 6 shows the number of differential proteins between the various control groups. The number of differential proteins in different pretreatment methods of the same substrate was significantly smaller than

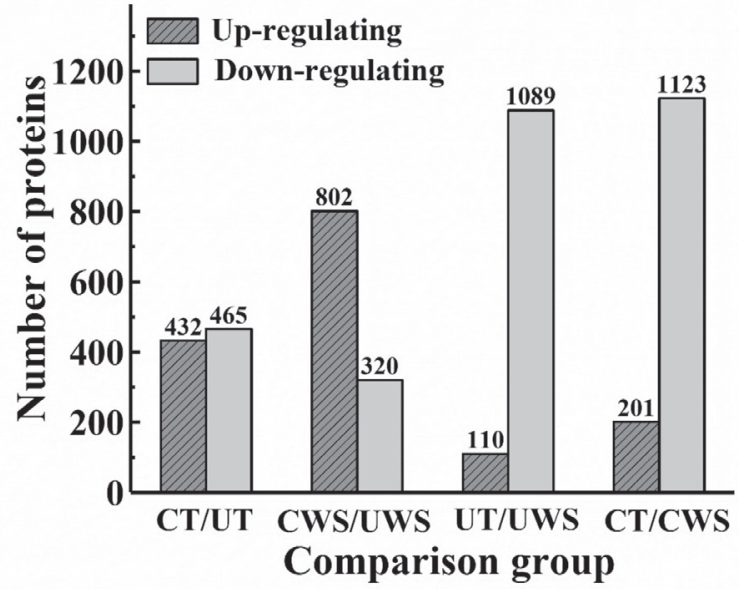

Fig. 6. Differential protein number histogram.

the number of differential proteins between different substrates. CT compared with UT, there are a total of 897 protein spots were found to change significantly, with 432 proteins up-regulated and 465 proteins downregulated. CWS compared with UWS, there are a total of 1122 protein spots were found to change significantly, with 802 proteins up-regulated and 320 proteins downregulated. UT compared with UWS, there are a total of 1199 protein spots were found to change significantly, with 110 proteins up-regulated and 1089 proteins downregulated. CT compared with CWS, there are a total of 1324 protein spots were found to change significantly, with 201 proteins up-regulated and 1123 proteins downregulated.

\section{Analysis of Differential Protein Biology Information}

UT, CT, UWS and CWS were used as protein samples to compare the secretion of A. fumigatus G-13 protein. The information on the significant changes in protein associated with lignin degradation is shown in Table 1. According to Table 1, 41 enzymes involved in the degradation of lignocellulose were identified, of which 2 enzymes were involved in cellulose degradation, namely cellulase and cellobiose dehydrogenase. There are 39 enzymes involved in lignin degradation, including indoleamine-2, 3-dioxygenase family protein, dioxygenase, fatty acid oxygenase PPOA, cytochrome P450 monooxygenase GLIC2, peroxisomal-3-ketoacyl COA thiolase KAT1, erulic acid esterase B-2, peroxisomal membrane protein PEX3, monooxygenase, bifunctional catalase peroxidase CAT2, fatty acid oxygenase PPOC, catechol dioxygenase, protoporphyrinogen oxidase, quinone oxidoreductase, catalase, CAT, ubiquinone biosynthesis monooxgenase COQ6, etc. CT compared to UT, there were 49 significantly differential proteins associated with lignin degradation, of which 22 were up-regulated and 27 were down-regulated. CWS compared to UWS, there were 49 significantly differential proteins associated with 
Table 1. Lignin degradation-related significant change protein information table.

\begin{tabular}{|c|c|c|c|c|c|}
\hline Protein_ID & Description & $\mathrm{UT} / \mathrm{CT}$ & UWS/CWS & $\begin{array}{c}\text { UT/ } \\
\text { UWS }\end{array}$ & $\mathrm{CT} / \mathrm{CWS}$ \\
\hline EAL84693.1 & Indoleamine-2,3-dioxygenase family protein & 0.23 & 0.09 & 0.32 & 0.21 \\
\hline EAL85498.1 & Dioxygenase & 0.25 & 1.10 & 0.35 & - \\
\hline KMK60141.1 & Flavin containing amine oxidase, putative & 1.39 & 1.54 & - & 1.28 \\
\hline KEY82638.1 & Glyoxylase & 1.09 & 1.43 & 1.51 & - \\
\hline KMK55985.1 & Oxidoreductase & 0.41 & 0.16 & 0.56 & 0.38 \\
\hline EDP50447.1 & Fatty acid oxygenase PPOA & 2.04 & 1.79 & - & 1.89 \\
\hline EAL87300.1 & Fructosyl amine oxidoreductase & 1.49 & 0.58 & 2.08 & 1.38 \\
\hline KMK58337.1 & Isoamyl alcohol oxidase, putative & 0.54 & 0.21 & 0.75 & 0.50 \\
\hline EAL85874.2 & Peroxisomal membrane protein PMP47 & 1.47 & 0.57 & 2.04 & - \\
\hline KMK58631.1 & Mycelial catalase CAT1 & 1.61 & 0.61 & 2.24 & 2.49 \\
\hline KMK60063.1 & Cytochrome P450 monooxygenase GLIC2 & 0.88 & 1.33 & 1.21 & 0.81 \\
\hline KEY82116.1 & Peroxisomal 3 ketoacyl COA thiolase KAT1 & 0.29 & 0.11 & 0.40 & 0.27 \\
\hline EDP49472.1 & Ferulic acid esterase B-2 & - & - & - & - \\
\hline EAL91965.1 & Peroxisomal membrane protein PEX3 & 2.13 & 0.81 & 2.92 & 1.95 \\
\hline EDP55336.1 & Monooxygenase, putative & 0.90 & 0.35 & 1.25 & 0.83 \\
\hline KEY79055.1 & Bifunctional catalase peroxidase CAT2 & 0.28 & 0.11 & 0.38 & 0.25 \\
\hline EAL84220.1 & Ferulic acid esterase B-1 & - & - & - & - \\
\hline KEY83653.1 & Cytochrome P450 monooxygenase & 0.29 & 0.11 & 0.40 & 0.27 \\
\hline KMK57185.1 & Hypothetical protein Y699_06726 & 2.13 & 1.82 & -- & 1.97 \\
\hline EDP50869.1 & Cytochrome P450 monooxygenase, putative & 1.85 & 0.71 & 2.56 & 1.70 \\
\hline KMK56018.1 & Amine oxidase & 0.26 & 0.10 & 0.35 & - \\
\hline KMK62928.1 & Cellulase, putative & 1.59 & 0.61 & 2.19 & 1.46 \\
\hline EAL90166.1 & Flavin-binding monooxygenase & 1.79 & 1.67 & 2.46 & 1.64 \\
\hline EAL88562.1 & B-glucancellobiohydrolase & 2.09 & 0.81 & - & 1.94 \\
\hline KEY75915.1 & Homogentisate-1,2-dioxygenase & 1.20 & 2.04 & 0.31 & 0.45 \\
\hline KEY82239.1 & Cellobiose dehydrogenase & 0.23 & 1.22 & 1.39 & - \\
\hline KEY78684.1 & Peroxidase, putative & 0.09 & 0.10 & 0.53 & 0.42 \\
\hline EAL91860.1 & Peroxisomal copper amine oxidase & 0.32 & 0.35 & 1.93 & 1.51 \\
\hline KMK60608.1 & Isoamyl alcohol oxidase & 0.21 & 0.23 & 1.28 & - \\
\hline EAL89751.1 & 3-demethylubiquinone-9-methyltransferase & 0.41 & 2.04 & 1.50 & 0.54 \\
\hline KMK57019.1 & O-methyltransferase, putative & 0.16 & 0.79 & 0.58 & 0.21 \\
\hline EAL86791.1 & Galactose oxidase & 0.56 & 2.86 & 2.08 & 0.75 \\
\hline EAL88473.1 & Ketone reductase & 0.38 & 1.89 & 1.38 & 0.50 \\
\hline EAL86587.1 & Catechol dioxygenase & 1.47 & 1.61 & 0.88 & 0.29 \\
\hline KEY84070.1 & Aldo keto reductase AKR & 0.57 & 0.62 & 0.34 & 0.11 \\
\hline EAL92901.1 & Pyridoxamine phosphate oxidase & 2.04 & 2.22 & 1.21 & 0.40 \\
\hline EAL85120.1 & $\begin{array}{c}\text { Fumagillin biosynthesis antibiotic biosynthesis mo- } \\
\text { nooxygenase superfamily monooxygenase }\end{array}$ & 1.35 & 1.49 & 0.81 & 0.27 \\
\hline KEY78179.1 & Fatty acid oxygenase PPOC, partial & 2.38 & 2.13 & 0.90 & 0.28 \\
\hline
\end{tabular}


Table 1. Continued.

\begin{tabular}{|c|c|c|c|c|c|}
\hline EAL93430.1 & Peroxisomal 3-ketoacyl-COA thiolase KAT1 & 0.91 & 0.81 & 0.35 & 0.11 \\
\hline EAL89119.1 & NADH-ubiquinone oxidoreductase & 3.29 & 2.94 & 1.25 & 0.38 \\
\hline KMK57661.1 & Catechol dioxygenase & 2.18 & 1.96 & 0.83 & 0.25 \\
\hline EAL88695.1 & Protoporphyrinogen oxidase & 1.12 & 0.29 & 2.14 & 1.85 \\
\hline KMK59768.1 & Quinone oxidoreductase & 0.43 & 1.11 & 0.82 & 0.71 \\
\hline EDP53821.1 & FAD monooxygenase, putative & 1.54 & 1.41 & 2.95 & 2.56 \\
\hline KEY82179.1 & Quinone oxidoreductase & 1.03 & 0.27 & 1.97 & 1.70 \\
\hline KEY83800.1 & Phytanoyl-coa dioxygenase family protein & 0.25 & 1.59 & 1.78 & 2.10 \\
\hline EAL93849.1 & FAD monooxygenase & 0.10 & 0.61 & 0.68 & 0.81 \\
\hline EAL86869.1 & A-ketoglutarate-dependent taurine dioxygenase & 0.35 & 2.17 & 2.46 & 2.91 \\
\hline KMK61241.1 & Catalase & 0.23 & 1.47 & 1.64 & 1.94 \\
\hline EAL89500.1 & Ubiquinone biosynthesis monooxgenase COQ6 & 0.19 & 1.20 & 1.16 & 0.91 \\
\hline EAL90759.1 & Catechol dioxygenase & 0.34 & 1.72 & 1.25 & 0.45 \\
\hline
\end{tabular}

lignin degradation, of which 25 were up-regulated and 24 were down-regulated. UT compared to UWS, there were 45 significantly differential proteins associated with lignin degradation, with 26 up-regulated and 19 down-regulated. CT compared to CWS, there were 43 significantly differential proteins associated with lignin degradation, with 17 up-regulated and 26 down-regulated. Comparing each comparison groups, 13 enzymes were highly expressed only after pretreatment (see UT/CT and UWS/CWS in Table 1), such as NADH-ubiquinone oxidoreductase, glyoxylase, flavin-binding monooxygenase, etc. It indicated that pretreatment could increase the expression of these 13 enzymes or induce the strains to produce these enzymes. Only 13 enzymes were highly expressed under the condition that lignocellulosic substrate was Robinia (see UT/UST and CT/CWS in 1), such as mycelial catalase CAT1, peroxisomal membrane protein (PEX3), $\alpha$-ketoglutarate-dependent dioxygenase, etc. The results showed that the composition and structure of natural lignocellulose from Robinia were more favorable for synthesis of these enzymes.

Fig. 7 show significant enrichment entries of UT, CT, UWS, and CWS, respectively. The ggplot2 is used to display the results of the GO enrichment analysis in the form of a scatter plot. According to the analysis, the CT/UT significant enrichment items are: extracellular region, endoplasmic reticulum membrane, proteolysis, ribosome, etc.; The CWS/UWS significant enrichment items are: extracellular region, cation binding, mitochondrial matrix, catabolism of polysaccharides, etc.; The UT/UWS significant enrichment items are: extracellular region, proteolysis, celluar cell wall organization, etc.; The CT/CWS significant enrichment items are: extracellular region, proteolysis, etc.

In organisms, different proteins coordinate with each other to perform their biological functions, and Pathway analysis helps to further understand protein biological functions. Pathway significant enrichment analysis is based on the KEGG pathway. Fig. 8 is a schematic diagram of Pathway enrichment of differentially abundant proteins compared with different substrates. The analysis shows that the CT/UT differential abundance protein pathways are: ribosome, starch and sucrose metabolism, sphingolipid metabolism, phenylpropanoid biosynthesis, etc.; The pathways for CWS/UWS differential abundance proteins are as follows: glycolysis/gluconeogenesis, starch and sucrose metabolism, and arginine and proline metabolism; The pathways for UT/UWS differential abundance proteins are as follows: oxidative phosphorylation, starch and sucrose metabolism, etc.; The pathways for $\mathrm{CT} / \mathrm{CWS}$ differential abundance proteins are as follows: glycolysis/gluconeogenesis, starch and sucrose metabolism, TCA cycle, etc.

\section{Results and Discussion}

\section{NADH-Ubiquinone Oxidoreductase}

NADH-ubiquinone oxidoreductase is the enzyme with the most increased expression before and after pretreatment. That is to say, NADH-ubiquinone oxidoreductase exhibits significant differential protein enrichment in both samples before and after pretreatment. It is generally believed that NAD dehydrogenase in the citric acid cycle provides energy input to the respiratory chain, coupling the oxidation of NADH with the reduction of panquinone to produce protons for ATP synthesis. This process generally occurs in the plasma membrane of mitochondria and purple photosynthetic bacteria in eukaryotes and is one of the largest catalytic complexes. The mechanism of 

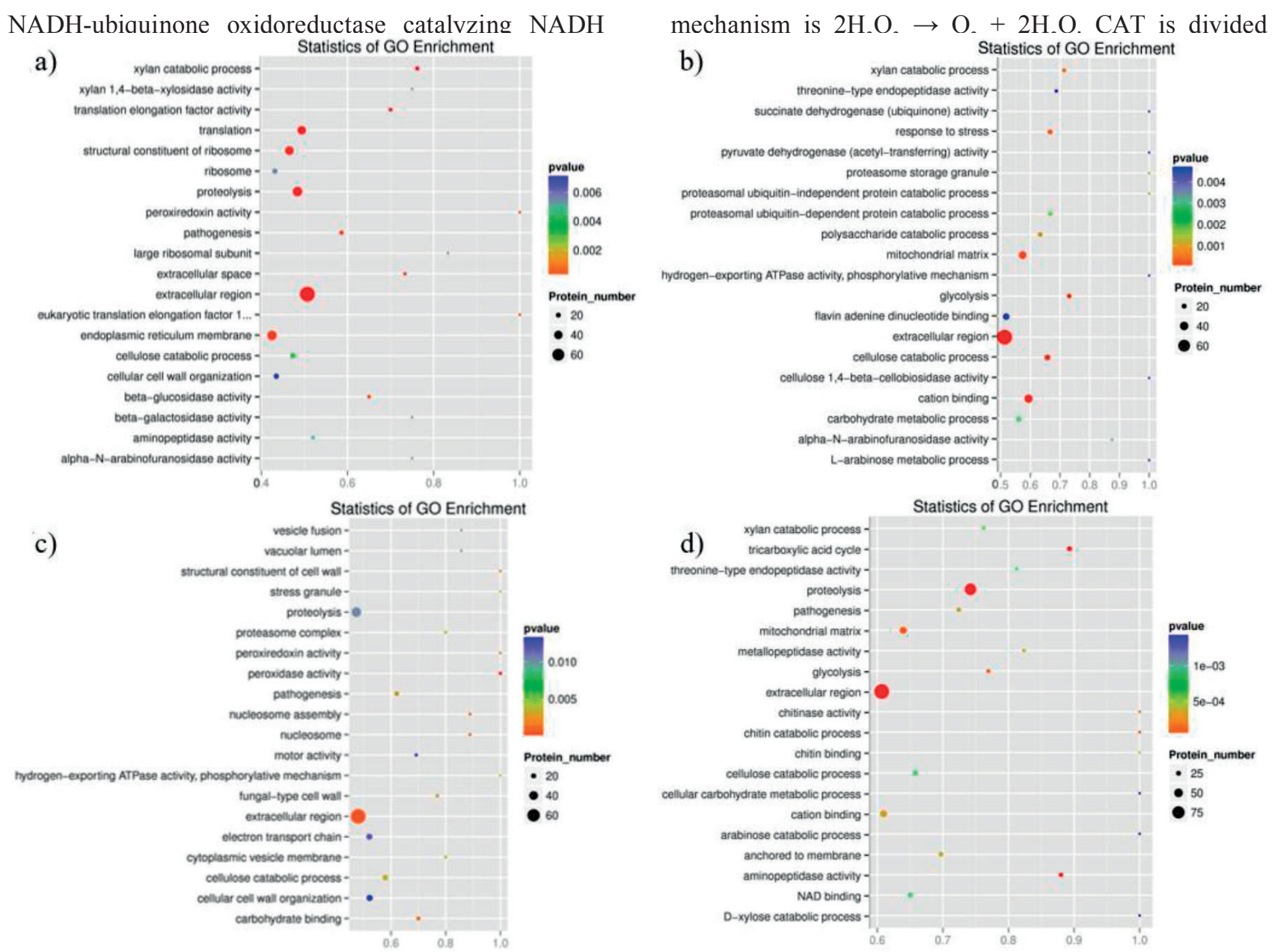

Fig. 7. GO enrichment scatter plot. a) $\mathrm{CT} / \mathrm{UT}$, b) $\mathrm{CWS} / \mathrm{UWS}$, c) UT/UWS, d) $\mathrm{CT} / \mathrm{CWS}$.

oxidation, ubiquinone reduction and $4 \mathrm{H}+\mathrm{NADH}$ transmembrane transfer were as follows: NADH + $\mathrm{H}^{+}+\mathrm{Q}+4 \mathrm{H}^{+} \mathrm{N} \Leftrightarrow \mathrm{NAD}^{+}+\mathrm{QH}_{2}+4 \mathrm{H}^{+}$[23]. After pretreatment, strain A. fumigatus $\mathrm{G}-13$ exhibited high lignin-degrading enzyme activity and high protein expression. It indicates that the pretreatment will change the surface structure of natural lignocellulose, affect carbon source and energy metabolism of the strain and production of related enzymes, and finally promote the respiration of mycelium. And it also provides energy for the growth of bacteria and the secretion of ligninase.

\section{Hyphae Catalase CAT1}

Catalase CAT1 is an enzyme widely present in aerobic microorganisms, animals and plants, with high catalytic efficiency and important industrial application value. It is widely used in food, environmental protection, papermaking, textile and other industries. Mycelium peroxidase refers to synthesized catalase on mycelium, which occurs in the growth and reproduction of almost all filamentous fungi. It protects cells from the toxic effects of hydrogen peroxide, and its catalytic into three subgroups according to the similarity of structure and sequence level, namely monofunctional catalase (typical catalase), bifunctional-CAT (catalaseperoxidase, CAT-POD) and manganese CAT. According to the difference in the structure of the catalytic center, it can be divided into two types: an iron-containing porphyrin structure and a manganese catalase containing a manganese ion instead of an iron porphyrin structure. In this study, hyphae catalase CAT1 is the enzyme with the highest increase in expression in different types of lignin. That is, whether pretreatment is carried out or not, this ligninase produced by strain A. fumigatus G-13 fermented Robinia is much higher than that of fermented walnut shell. However, it is not that the higher the expression of hyphal catalase CAT1, the higher activity of lignin-degrading peroxidase (In this study, the Lac activity of natural lignin substrate fermented by A. fumigatus G-13 was much lower than that of $\mathrm{LiP}$ and $\mathrm{MnP}$ ). The possible reason is that the total content of hyphae catalase CAT1 produced by $A$. fumigatus G-13 fermenting natural lignin with Robinia as substrate is increased, but the factors affecting of ligninase producting by A. fumigatus are also fermentation produces, included differences in energy 

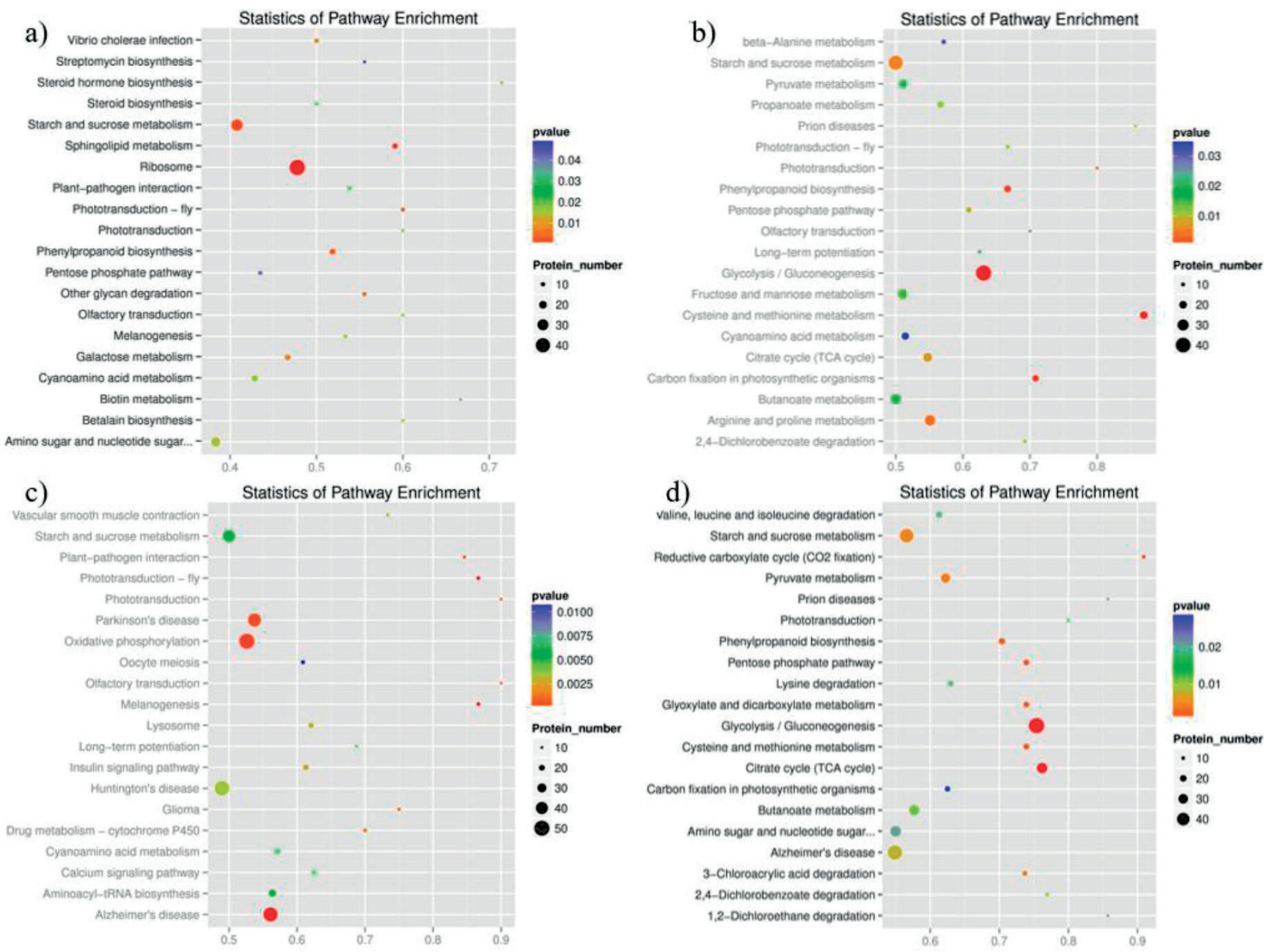

Fig. 8. Pathway enrichment diagram. a) CT/UT, b) CWS/UWS, c) UT/UWS, d) CT/CWS.

and nucleotide metabolism by the substrate. And the site where the strain synthesizes catalase also includes membrane peroxidase and the like.

\section{Feruloyl Esterase}

Feruloyl esterase (EC 3.1.1.73, FAE) belongs to the family of hydrolases, which can hydrolyze the ester bond in methyl ferulate, oligosaccharide ferulic acid ester and polysaccharide ferulic acid ester. It can cut off the cross-linking between polysaccharide-polysaccharide and polysaccharide-lignin in the cell wall, which is beneficial to the degradation of polysaccharides and the release of lignin in cell wall materials [24, 25]. Studies have shown that feruloyl esterase can play an important role in the degradation of lignin. When we used the lignin model compound as substrate, we also found that A. fumigatus G-13 produced a large amount of feruloyl esterase. In the process of ligninase production induced by natural lignin as substrate, feruloyl esterase did not show significant enrichment difference by changing the types of lignin samples and pretreatment. Its secretion has been suppressed. The reason may be related to the fact that ferulic esterase is an inducible enzyme, which may affect the secretion only when the lignin composition of the substrate is changed. The Robinia and walnut shells belong to hardwood vegetation. Walnut shell lignin is a typical SGH type lignin. The proportion of S-type unit to G-type unit in this lignin molecule is close, and the content is much higher than H-type structural unit. The cellulose content of Robinia is higher, but the main lignin structure types are also $\mathrm{S}$ type and $\mathrm{G}$ type. Therefore, in the case of A. Fumigatus G-13 fermentation, although there was a large difference in ligninase activity in the four comparison groups, there was no significant difference in the expression of feruloyl esterase.

\section{Other Differential Protein Enrichment Analysis}

\section{Carbon Metabolism Related Proteins}

At the stage of $A$. fumigatus G-13 induction of protein production, natural lignocellulose is used as the sole carbon source and energy source to supply the expression of foreign proteins. The catalysis of ester and ether linkages between lignin structural units is the first step in lignin metabolism. Subsequently, an enzyme such as catalase CAT1 converts hydrogen 
peroxide to $\mathrm{H}_{2} \mathrm{O}$ during oxidation of the substrate, and formaldehyde is converted to dihydroxyacetone (DHA) and 3-phospho-glyceraldehyde by dihydroxyacetonease DAS1 or DAS2. The three proteins involved in methyl metabolism, AOX1, CAT1 and DAS2, were significantly up-regulated in UT and CT during this process. It is generally believed that a monocyclic aromatic compound undergoes a ring opening reaction through a catechol or protocatechuic acid pathway under the action of a dehydrogenase, a decarboxylase, and a dioxygenase to produce an intermediate metabolite of $\beta$-ketoadipate. The intermediate metabolite of $\beta$-ketoadipate binds to Coenzyme A, decomposes into acetyl-CoA and succinic acid via the $\beta$-ketoadipate pathway, and finally enters the TCA cycle, which is also accompanied by oxidation of the methyl group [26]. In both samples, the expression levels of two proteins involved in glutathione (GSH) metabolism, DUT1 and URE2, were up-regulated. Studies by shEN Q et al. have shown that GSH can promote methylation metabolism in the body, accelerate the methylation process in the body, and ultimately increase the content of end products of methyl metabolism, thereby promoting total metabolism [27]. At the same time, more energy is needed to maintain the growth and reproduction of its own cells. The results showed that pretreatment increased the Methyl metabolic capacity of strain $A$. fumigatus $\mathrm{G}-13$.

\section{Energy and Nucleotide Metabolism Related Proteins}

Energy and nucleotide metabolism have significant effects on the growth, reproduction and enzyme production of $A$. fumigatus G-13. Using the pretreated sample to study the process of fermenting natural lignin by strain $A$. fumigatus $\mathrm{G}-13$, it was found that the transcription level of nucleic acid associated with the electron transport system was up-regulated (eg ATP20, PPA2 and VMA5 proteins), but the QCR2 protein involved in the pan-cytochrome $\mathrm{C}$ reductase is down-regulated [28]. Nucleic acid metabolismrelated proteins did not change significantly in unpretreated samples except for the up-regulation of ADE12 involved in metabolism. The expression of the two proteins ADE6 and ADE1 related to nucleic acid metabolism was down-regulated after pretreatment, but the expression levels of the three proteins ADE2, ADE17 and RPB3 were up-regulated. The results showed that pre-treatment stimulated the growth of cells compared with the unpretreated samples, resulting in enhanced activity of related enzymes in the metabolism of deoxyribonucleotides during the growth and reproduction of fungal cells. The synthesis of related substances is increased, and the intermediate substances in metabolism are also synthesized as much as possible for the synthesis of ribonucleotides and deoxyribonucleotides.

\section{Conclusion}

The Robinia and walnut shells pretreated with $\mathrm{Ca}(\mathrm{OH})_{2}$ solution were fermented by $A$. fumigatus G-13, and the activity of lignin degrading enzyme was significantly improved. Cluster analysis, GO enrichment analysis and Pathway enrichment analysis showed that the differential proteins related to degradation of natural lignocellulose substrate fermented by $A$. fumigatus G-13 were mainly concentrated in carbon source metabolism, energy and nucleotide metabolism. The pretreated lignocellulosic substrate was induced to undergo protein production by $A$. fumigatus $\mathrm{G}-13$, the proteins involved in methyl metabolism and glutathione metabolism were significantly upregulated. It is shown that the pretreatment of $\mathrm{Ca}(\mathrm{OH})_{2}$ solution can enhance the methyl metabolism ability of the strain. The carbon source, energy and nucleotide metabolism of the strain were also enhanced, which promoted mycelial respiration and provided energy for the growth of the strain and the secretion of ligninase. The results of the study explored the induction of substrate, and analyzed the high expression of lignin degrading enzyme after pretreatment, which provided a useful basis for its application in lignocellulosic biomass energy.

\section{Acknowledgement}

This study was financially supported by the National Natural Science Foundation of China (NO: 21776054).

\section{Conflict of Interest}

The authors declare no conflict of interest.

\section{References}

1. DERECA W., MD N., MAHESH H., ALFRED T.-N., SHAIK J. Extraction and characterization of lignin from different biomass resources. Journal of Materials Research and Technology 4, 26, 2015.

2. TAO Y.Z, GUAN Y.T. The study of chemical composition of lignin and its application. Journal of Cellulose Science and Technology 11, 42, 2003.

3. ZHANG N., WANG L., ZHANG K., WALKER T. THY P., JENKINS B., ZHENG Y. Pretreatment of lignocellulosic biomass using bioleaching to reduce inorganic elements. Fuel 246, 386, 2019.

4. PARVEEN K., DIANE M.B., MICHAEL, J.D., PIETER S. Methods for pretreatment of lignocellulosic biomass for efficient hydrolysis and biofuel production. Industrial \& Engineering Chemistry Research 48, 3713, 2009.

5. TEERAVIVATTANAKIT T., BARAMEE S., PHITSUWAN P., SORNYOTHA S., WEAONUKUL R., PASON P., TACHAAPAIKOON C., POOMPUTSA K., KOSUGI A., SAKKA K., RATANAKHANOKCHAI K. Chemical pretreatment-independent saccharifications of xylan and cellulose of rice straw by bacterial weak lignin- 
binding xylanolytic and cellulolytic enzymes. Applied and Environmental Microbiology 83, 2017.

6. JIN X.C., LIU G.Q., XU Z.H., TAO W.Y. Decolorization of a dye industry effluent by Aspergillus fumigatus XC6. Applied microbiology and biotechnology 74, 239, 2007.

7. RAJESH K.P., SOUMYA C., PRANAB B.M., SANTOSH K.G., SONIKA S., MOHAN G.V., SIBNARAYAN D., SANJAI K.D., DHARMENDRA K.G. Bioethanol production from waste lignocelluloses: A review on microbial degradation potential, Chemosphere 231, 588, 2019.

8. FRANCESCO C. The biorefinery concept: using biomass instead of oil for producing energy and chemicals. Energy Conversion Management 51, 1412, 2010.

9. CHEN H., LIAO C.J., FENG S., FENG W.C., FAN G.Z., SONG G.G., XIE Y.X. Study on extraction of rice straw cellulose by acid and alkali treatment. Jiangsu agricultural science 42, 252, 2014.

10. DEANGELIS K.M., SHARMA D., VARNEY R., SIMMONS B., ISERN N.G., MARKILLLIE L.M., NICORA C., NORBECK A.D., TAYLOR R.C., ALDRICH J.T., ROBINSON E.W. Evidence supporting dissimilatory and assimilatory lignin degradation in Enterobacter lignolyticus SCF1. Frontiers in Microbiology 4, 280, 2013.

11. SUNIL S.A., AN A.L., ARULMANI M., PETER P., SIU K.S. Quantitative iTRAQ secretome analysis of Aspergillus niger reveals novel hydrolytic enzyme. Journal of proteome research 9, 3932, 2010.

12. LIANG W.Q., WANG Z.Y., LI H., WU P.C., HU J.M., LUO N., CAO L.X., LIU Y.H. Purification and characterization of a novel pyrethroid hydrolase from Aspergillus niger ZD11. Journal of agricultural and food chemistry 53, 7415, 2005.

13. COUTURIER M., NAVARRO D., CHEVRET D., HENRISSAT B., PIUMI F., FRANCISCO J.R.D, ANGEL T.M., GRIGORIEV I.V., RILEY R., LIPZEN A., BERRIN J.G., MASTER E.R., ROSSO M.N. Enhanced degradation of softwood versus hardwood by the white-rot fungus Pycnoporus coccineus. Biotechnology for Biofuel 8, 216, 2015.

14. ANAMIKA R., SAYALI S., PATRICIA A.C., STEVEN D.H., ROLF P., ANDREW J.M. Phanerochaete chrysosporium produces a diverse array of extracellular enzymes when grown on sorghum, Applied Microbiology and Biotechnology 93, 2075, 2012.

15. PATYSHAKULIYEAV A., POST H., ZHOU M., JURAK E., HECK A.J., HILDEN K.S., KABEL M.A., MAKELA M.R., ALTELAAR M.A., DE VRIES, R.P. Uncovering the abilities of Agaricus bisporus to degrade plant biomass throughout its life cycle. Environmental Microbiology 17, 3098, 2015

16. DING S.Y., LIU Y.S., ZENG Y.N., HIMMEL M.E., BAKER J.O., BAYER E.A. How does plant cell wall nanoscale architecture correlate with enzymatic digestibility? Science 338, 1055, 2012.

17. ELISA V., ANGEL T.M., MARIA J.M. Molecular cloning of aryl-alcohol oxidase from the fungus Pleurotus eryngii, an enzyme involved in lignin degradation. Biochemical Journal 341, 113, 1999.

18. PAUL A., ERIKSSON K.-E. The importance of phenol oxidase activity in lignin degradation by the whiterot fungus Sporotrichum pulverulentum. Archives of Microbiology 109, 1, 1976.

19. TIEN M., KIRK T.K. Lignin-degrading enzyme from the hymenomycete Phanerochaete chrysosporium Burds. Science 221, 661, 1983.

20. CAI C., XU W.P., I X., FERGUSON I. Accumulation of lignin in relation to change in activities of lignification enzymes in loquat fruit flesh after harvest. Postharvest Biology and Technology 40, 163, 2006.

21. MANAVALAN A., ADAV S.S., SZE S.K. iTRAQbased quantitative secretome analysis of Phanerochaete chrysosporium. Journal of Proteomics 75, 642, 2011.

22. DASHTBAN M., SCHRAFT H., SYED T.A., QIN W.S. Fungal biodegradation and enzymatic modification of lignin 1, 36, 2010.

23. XU T., LI H., LU S.S., ZHANG H.Q., GE J.B. Research progress of mitochondrial electron transport chain and its biological significance 2, 250, 2015.

24. CRISTABELL P. Feruloyl esterase: A principal biodegradative enzyme. Bioprospects of Coastal Eubacteria 209, 2015.

25. KOSEKI T., FUSHINOBU S., SHIRAKAWA A.H., KOMAI M. Occurrence, properties, and applications of feruloyl esterases. Applied Microbiology and Biotechnology 84, 803, 2009.

26. LV R.R. Metaproteomics analysis and identification of lignocellulose degradation-related enzymes. Fujian Normal University 2010.

27. SHEN Q. In vitro transport of neferine and its analogues and cytotoxicity of its reactive metabolites. Zhejiang University 2014.

28. ZHANG P.P. Characterization and metabolic mechanism of lignin biodegradation by Comamonas serinivorans C35. Jiangsu University 2017. 